\title{
The increasing Parkinson's disease incidence rates: A call for collaboration
}

\author{
Sergio A. Castillo-Torres, Carlos A. Soto-Rincón, Beatriz Chávez-Luévanos and Ingrid Estrada-Bellmann* \\ Servicio de Neurología, Hospital Universitario “Dr. José Eleuterio González”, Universidad Autónoma de Nuevo León, Monterrey, N.L., México
}

To the Editor,

It was with greatinterest that we read Rodríguez-Violante et al's. article on the last issue of Rev Mex Neuroci, regarding the incidence rates of Parkinson's disease (PD) in Mexico in the 2014-2017 period'; the authors report an increase of $26.7 \%$ in the average annual percent change from 2014 to 2017. We believe this to be an extremely valuable contribution, being the first nation-wide study on the subject; notwithstanding the limitations, the authors draw our attention to an ever-growing menace: the burden of PD.

$\mathrm{PD}$ is the second most common neurodegenerative disease, only second in frequency to Alzheimer's disease. In 2017, the Global Burden of Neurological Disease reported that PD was the only one with increasing rates of prevalence, disability and death ${ }^{2}$. Last year, the Global Burden of PD study published in The Lancet Neurology ${ }^{3}$ reported that worldwide 6.1 million individuals were living with $\mathrm{PD}$, a dramatic increase from the 2.5 million in 1990; emphasizing PD as the fastest-growing neurodegenerative disorder and the need for further epidemiological and clinical studies.

As the number is projected to dramatically increase up to even 17 million worldwide in $2040^{4}$, some authors have advocated taking action on the oncoming PD pandemic $^{5}$. This call of action requires an interdisciplinary and multicenter collaboration between clinicians and other allied healthcare professionals across the country. May this article serve as our own national call for collaboration on the PD pandemic. As Professor Baastian Bloem from the Netherlands declared on the $5^{\text {th }}$ World Parkinson Congress (June 4-7, Kyoto, Japan): "Collaboration is the new competition. Don't do it alone."

\section{Conflicts of interest}

The authors declare that there are no conflicts of interest.

\section{Funding}

No specific funding was received for the present article.

\section{References}

1. Rodríguez-Violante $M$, Velásquez-Pérez $L$, Cervantes-Arriaga $A$. Incidence rates of Parkinson's disease in Mexico: analysis of 2014-2017 statistics. Rev Mex Neurociencia. 2019;20:136-40.

2. Group GBDNDC. Global, regional, and national burden of neurological disorders during 1990-2015: a systematic analysis for the global burden of disease study 2015. Lancet Neurol. 2017;16:877-97.

3. GBD 2016 Parkinson's Disease Collaborators. Global, regional, and national burden of Parkinson's disease, 1990-2016: a systematic analysis for the global burden of disease study 2016. Lancet Neurol. 2018;17:939-53.

4. Dorsey ER, Sherer T, Okun MS, Bloem BR. The emerging evidence of the Parkinson pandemic. J Parkinsons Dis. 2018;8:S3-8.

5. Dorsey ER, Bloem BR. The Parkinson pandemic-a call to action. JAMA Neurol. 2018;75:9-10.

\section{Correspondence:}

*Ingrid Estrada-Bellmann

Servicio de Neurología

Hospital Universitario "Dr. José Eleuterio González"

Universidad Autónoma de Nuevo León

Madero y Gonzalitos, s/n

Col. Mitras

Date of reception: 20-06-2019

Date of acceptance: 16-07-2019

DOI: 10.24875/RMN.19000103
Available online: 09-08-2019

Rev Mex Neuroci. 2019;20(4):207-207

www.revmexneurociencia.com

E-mail: ingridestmann @ hotmail.com

1665-5044/O 2019. Academia Mexicana de Neurología A.C. Published by Permanyer México. This is an Open Access article under the terms of the CC BYNC-ND license (http://creativecommons.org/licenses/by-nc-nd/4.0/). 